http://jmscr.igmpublication.org/home/ ISSN (e)-2347-176x ISSN (p) 2455-0450 crossref DOI: https://dx.doi.org/10.18535/jmscr/v9i6.25

\title{
Pedunculated Cardiac Mass (Fibroelastoma) in right Atrium and Anterior Mitral Valve Leaflet Prolapse in a Patient with Diabetic Ketoacidosis Diagnosed as DENOVO Type 1 Diabetes Mellitus: Case Report
}

\author{
Authors \\ Dr Rajendra Prasad, Dr Snigda Panuganti, Dr Balu Banoth, \\ Dr Alla Krishnakar Reddy \\ Department of General Medicine \\ SVS Medical College and Hospital, Mahabubnagar, Telangana, India
}

\begin{abstract}
Few studies report an increased incidence of mitral valve prolapse in patients with type $1 \mathrm{DM}$, and a benign primary cardiac tumor like Papillary fibroelastoma, has potentially life-threatening complications. We report a patient with an initial diagnosis of diabetic ketoacidosis, his Echocardiography showed a pedunculated mass attached to the roof of right atrium with anterior mitral leaflet prolapse, mild MR, mild LV dysfunction and minimal pericardial effusion. This patient was treated for DKA ,sugars corrected and advised treatment with insulin and advised regular follow up to monitor and prevent complications
\end{abstract}

Keywords: Papillary fibroelastoma, Diabetic ketoacidosis, mitral valve prolapsed.

\section{Introduction}

Mitral valve prolapse (MVP) affects 1 in 40 people in the general population ${ }^{(1)}$, and it is the primary indication for mitral valve (MV) surgery. Myxomatous degeneration, chordal rupture, and mitral regurgitation (MR) indicate the primary role of valvular disease. Traditionally, ventricular remodeling has been considered secondary to volume overload, by acting through b-adrenergic, cellular, and metabolic reductions in contractility leading to heart failure ${ }^{(2, \underline{3})}$.

It was suspected for several years that there is increased incidence of mitral valve prolapsed in patients with type 1 DM. In a study it was found that 190 out of 421 patients with type $1 \mathrm{DM}$ had Mitral valve prolapse was suspected clinically by the presence of mid systolic click, with or without late systolic murmur , and was confirmed by a two dimensional echocardiograph ${ }^{(4)}$

The prevalence of MVP, defined by echocardiography in most patients with age less than 40 yrs varies between $5-15 \%$ in literature and is $8 \%$ in their echocardiographic laboratory this association was statistically significant with a $\mathrm{P}$ value of $<0.0001^{(4)}$

Cardiac tumors are a rare, with an incidence rate of $0.02 \%$ revealed in autopsy ${ }^{(5)}$, but potentially curably form of heart disease. Presently, M-mode and two-dimensional echocardiography are utilized as safe, reliable, and noninvasive imaging modalities. Seventy-five per cent of these tumors are benign, with myxoma accounting for $50 \%$ and rhabdomyoma comprising $20 \%$ of lesions, papillary fibroeslastoma accounts for $5 \%$ of 
primary cardiac tumors ${ }^{(6)}$. Various histologic types of sarcomas are the predominant malignant cardiac neoplasms. With strict attention to avoiding perioperative tumor embolization, surgical resection of these lesions can be accomplished with minimal morbidity and mortality.

\section{Case Report}

A 28 -year-old male presented to the emergency department with acute shortness of breath. Over the preceding three days, he experienced decreased appetite, and gradually developed shortness of breath, which increased in severity over few hours.

Patient had lost 2-3 kgs weight in last 1 month duration. Patient had no symptoms of fever, cough ,cold ,chest pain. No history of similar complaints in the past. $\mathrm{He}$ is not a known case of diabetes mellitus ,hypertension .The family history was negative for neurologic diseases, cardiovascular diseases and neoplasms. A positive family history for type 1 diabetis mellitus is present, as patients father was known case of diabetes mellitus type 1 . On physical examination, he is thin build and moderately nourished, no pallor, ictrus, clubbing, cyanosis, lymphedenopathy, edema, neurocutaneous markers, his height was $180 \mathrm{cms}$ and weight of $60 \mathrm{kgs}$,arm span of $185 \mathrm{cms}$ and arm span to height ratio of 1.02

His blood pressure was $120 / 90 \mathrm{mmHg}$ and his pulse was 128 beats/ min. The respiration was 32beats $/ \mathrm{min}$. The body temperature was $38.5^{\circ} \mathrm{C}$, oxygen saturation on room air showed $99 \%$, His Glasgow Coma Scale was E4M6V5 and his lung sounds were clear. He had rapid heartbeats with a mid systolic click present in mitral area. His abdomen was soft and non tender .No focal neurological deficit. His skin turgor was decreased. Petechiae or subcutaneous nodule were absent.

Laboratory tests revealed a high blood glucose level of $>500 \mathrm{mg} / \mathrm{dl}$ and ketone body were positive. Arterial blood gas showed a $\mathrm{pH}$ of 7.04 , $\mathrm{PCO} 2$ of $9.8 \mathrm{mmHg}, \mathrm{PO} 2$ of $135 \mathrm{mmHg}$ and
HCO3 - of $2.5 \mathrm{meq} / \mathrm{L}$. The sodium, potassium, creatinine, and blood urea nitrogen were 126 $\mathrm{mmo} / \mathrm{L}, 5.0 \mathrm{mmol} / \mathrm{L}, 1.3 \mathrm{mg} / \mathrm{dL}$ and $57 \mathrm{mg} / \mathrm{dL}$, respectively. The white blood cell count was 18000 cells/uL with $90 \%$ of neutrophil. C-reactive protein level was positive (more than $12 \mathrm{mg} / \mathrm{lit}$ ). HBA1c 14.8\% .Electrocardiogram (ECG) showed sinus tachycardia. HRCT chest was normal. Ultrasound abdomen was normal. Opthal examination showed normal visual acuity and fundus examination. Thyroid profile was normal. Growth hormone and cortisol values were normal. Dehydration corrected with fluids and insulin replacement therapies were immediately started. Empiric antibiotic therapy was administered. On hospital day 2, the patient shortness of breath was reduced .2nd day lab investigations showed sodium $-134 \mathrm{meq} / 1$, potassium $-3.5 \mathrm{meq} / \mathrm{l}$. ABG showed PH 7.24, PCo2 - 11.6mmhg, HCO3 $4.8 \mathrm{mmol} / 1$.serum lactate $-12.6 \mathrm{mg} / \mathrm{dl}$.A repeat ECG showed sinus tachycardia.C Peptide value $0.25 \mathrm{ng} / \mathrm{ml}$.

Transthoracic echocardiography (TTE) showed a pedunculated mobile mass in the roof of right atrium, highly suggestive of papillary fibroelastoma and had anterior mitral valve prolapse with fleshy leaflets, mild MR, mild Left ventricular dysfunction ,ejection fraction of $50 \%$, with minimal pericardial effusion ,but no regional wall motion abnormality. Patient recovered over next 2 days and blood sugars were controlled on insulin therapy and $\mathrm{ABG}$ Values returned to normal and WBC count was normal at discharge.

\section{Discussion}

DKA is an acute complication of diabetes; its annual incidence rate is estimated to be 4.6-8.0 episodes per 1000 patients with diabetes ${ }^{(9,10)}$. Most patients with DKA are type 1 diabetes. DKA is a state of absolute or relative insulin deficiency coupled with elevated counter-regulatory hormones. Infection is the major precipitating factor followed by non-compliance of medication and new-onset diabetes mellitus. The other acute causes include pancreatitis, trauma, myocardial 
infarction, cerebrovascular accident, drugs, and psychological problems. Because of advances in the clinical recognition and management, the mortality rates have fallen from $7.96 \%-12.9 \%$ to $0.67 \%-2.65 \%$. However, the poor prognosis is observed in the elderly patients and anyone with severe comorbidities ${ }^{(8)}$. Thus, investigating the possible concurrent illness in all DKA admissions is crucial.

In our patient, there was family history of type 1 DM and he presented with DKA and elevated WBC counts thought the cause of infection could not be identified.He had sinus thacycardia on EKG on 2DECHO there was a pedunculated mass attached to the roof of right atrium with mitral valve prolapse and mild LV dysfunction and mild pericardial effusion .No signs suggestive of any connective tissue disorder.

With advances in technology and better awareness of primary cardiac tumor, a presumptive diagnosis of papillary fibroelastoma is possible through echocardiography, especially TEE. Alternative cardiac CT and MRI may have limitations in detecting small mobile masses. The clinical presentations vary from asymptomatic to severe embolic complications. A comprehensive analysis estimated that $30 \%$ of patients were asymptomatic and incidentally diagnosed ${ }^{(12)}$. Symptoms such as transient ischemic attack, stroke, visual loss, angina, myocardial infarction, heart failure, mesenteric ischemia, renal infarction, limb ischemia, pulmonary embolism, syncope and sudden death have been reported. The most symptoms are attributed to embolism from the fronds of the tumor itself or thrombi on the tumor surface. Some complications result from a direct occlusion of coronary artery ostium or narrowing of the ventricular outflow tract. Most patients do not have a history of valvular disease, and papillary fibroelastomas can be safely excised with native valve preservation and low recurrence rate. At follow-up, patients without surgical treatment were more predisposed to stroke and death than those with surgical treatment ${ }^{(11)}$. However, no data are present explaining whether medical management with antiplatelet or anticoagulation improves outcomes. In our case patient had asymptomatic cardiac tumor which require further follow up and monitoring to look for any symptoms seen in few cases like stroke, myocardial infraction.

A similar situation has been reported in a different case report, where a case with initial diagnosis of diabetic ketoacidosis, on Magnetic resonance imaging of brain showed a recent infarct at right temporal lobe. Non ST-segment elevation myocardial infarction (NSTEMI) was noted on hospital day 2. Echocardiography revealed normal wall motion and a $1-\mathrm{cm}$ pedunculated mass at the aortic valve without aortic regurgitation. The tumor was thought to be responsible for cerebral infarction and NSTEMI that accelerated diabetic decompensation. The patient underwent surgical excision, and the histological feature was consistent with a papillary fibroelastoma ${ }^{(8)}$. Thus cases with cardiac mass require regualar follow up and necessary workup to look for and prevent complications by doing a surgical excision if necessary.

\section{Conclusion}

According to our review of relevant literature, this is the report of DKA as presentation in a patient with type $1 \mathrm{DM}$, cardiac papillary fibroelastoma and mitral valve prolapsed.

\section{References}

1. Freed LA, Levy D, Levine RA, et al. Prevalence and clinical outcome of mitral-valve prolapse. $N$ Engl $J$ Med 1999;341:1-7.

2. Pu M, Gao Z, Zhang X, et al. Impact of mitral regurgitation on left ventricular anatomic and molecular remodeling and systolic function: implication for outcome.Am J Physiol Heart Circ Physiol 2009;296:H1727-32

3. Beeri R, Yosefy C, Guerrero JL, et al. Mitral regurgitation augments postmyocardial infarction remodeling failure 
of hypertrophic compensation. J Am Coll Cardiol 2008;51:476-86.

4. David SH Bel, Ronald T Acton. Diabetes Care Jun 1996, 19 (6) 672; Increased Prevalence of Mitral Valve Prolapse in IDDM .DOI: 10.2337/diacare.19.6.672

5. Reynen K. Frequency of primary tumors of the heart. Am J Cardiol 1996; 77: 107

6. Straus R, Merliss R. Primary tumor of the heart. Arch Pathol 1945: 39:74.

7. Levine RA, Jerosch-Herold M, Hajjar RJ. Mitral Valve Prolapse: A Disease of Valve and Ventricle. $J$ Am Coll Cardiol. 2018;72(8):835-837. doi:10.1016/j.jacc.2018.07.006

8. H. C. Hsu, S. Y. Tsao, S. M. Hou, S. W. Hsieh, and Y. C. Yeo . Papillary Fibroelastoma and Diabetic Ketoacidosis DOI : 10.6314/JIMT.2017.28(1).07

9. Kitabchi AE, Umpierrez GE, Murphy MB, et al. Management of hyperglycemic crises in patients with diabetes mellitus. Diabetes Care 2001; 24: 131-53.

10. Liu CC, Chen KR, Chen HF, et al. Trends in hospitalization for diabetic ketoacidosis in diabetic patients in Taiwan: analysis of national claims data 1997-2005. J Formos Med Assoc 2010; 109: 725-34.

11. Tamin SS, Maleszewski JJ, Scott CG, et al. Prognostic and bioepidemiologic implications of papillary fibroelastomas. $\mathbf{J}$ Am Coll Cardiol 2015; 65: 2420-9.

12. Gowda RM, Khan IA, Nair CK, et al. Cardiac papillary fibroelastoma: a comprehensive analysis of 725 cases. Am Heart J 2003; 146: 404-10. 